MIDAS

Museus e estudos interdisciplinares

$12 \mid 2020$

Varia

\title{
Tula Giannini e Jonathan P. Bowen (ed.) - Museums and Digital Culture: New Perspectives and Research
}

\section{Margarida Melo Sampaio}

\section{(2) OpenEdition}

\section{Journals}

\section{Edição electrónica}

URL: https://journals.openedition.org/midas/2346

DOI: $10.4000 /$ midas. 2346

ISSN: 2182-9543

\section{Editora:}

Alice Semedo, Paulo Simões Rodrigues, Pedro Casaleiro, Raquel Henriques da Silva, Ana Carvalho

\section{Refêrencia eletrónica}

Margarida Melo Sampaio, «Tula Giannini e Jonathan P. Bowen (ed.) - Museums and Digital Culture: New Perspectives and Research», MIDAS [Online], 12 | 2020, posto online no dia 14 novembro 2020, consultado no dia 04 março 2022. URL: http://journals.openedition.org/midas/2346 ; DOI: https:// doi.org/10.4000/midas.2346

\section{Este documento foi criado de forma automática no dia 4 março 2022.}

\section{cc) (†) (-)}

Midas is licensed under a Creative Commons Attribution-NonCommercial-ShareAlike 3.0 International License 


\title{
Tula Giannini e Jonathan P. Bowen (ed.) - Museums and Digital Culture: New Perspectives and Research
}

\author{
Margarida Melo Sampaio
}

\section{REFERÊNCIA}

Giannini, Tula, e Jonathan P. Bowen, ed. 2019. Museums and Digital Culture: New Perspectives and Research. Springer Series on Cultural Computing. Cham: Springer. 590 páginas, ISBN 978-3-319-97457-6.

1 O livro Museums and Digital Culture: New Perspectives and Research debruça-se sobre a cultura digital, as práticas artísticas digitais e o seu impacto nos museus no século XXI, traçando o desenvolvimento da cultura digital desde os anos de 1940 até ao presente. ${ }^{1}$ Sob múltiplos pontos de vista, esta publicação reflecte sobre o crescente $\mathrm{e}$ preponderante papel dos meios digitais na sociedade e o consequente impacto nos diferentes aspectos da prática museal. Os temas abordados visam responder a algumas das seguintes questões: que desafios e oportunidades oferecem as tecnologias aos museus? Que competências digitais são essenciais? De que forma irão os museus transformar-se perante a complexa e evolutiva paisagem cultural digital? De que forma a cultura digital irá impactar a sociedade, a cultura e a identidade das instituições? Onde residirá o museu no futuro? Irão os museus transformar-se em "Disneylândias"?

2 A publicação é organizada sob a direcção de Tula Giannini e Jonathan P. Bowen, que ao longo dos últimos anos têm publicado conjuntamente diversos artigos sobre o tema em apreço, entre os quais destacamos: "Digitalism: The New Realism?" (2014), "Curating Digital Life and Culture: Art and Information" (2016). Tula Giannini é professora na School of Information no Pratt Institute em Nova Iorque, tendo dirigido projectos colaborativos entre museus e bibliotecas. Jonathan P. Bowen é professor emérito de Computação na London South Bank University e tem colaborado de forma regular com a conferência 
Museums and the Web. O livro reúne contributos dos seus editores, mas também de outros autores, que partem de vários campos de investigação, apresentando perspectivas diversas sobre o museu do século XXI e reflectindo sobre cultura digital e comportamentos digitais, interacções entre real e virtual, e do modo como impacta estratégias, planeamentos e práticas, num mundo em que a cultura digital redefine todos os dias o comportamento humano. Neste contexto, o livro centra-se principalmente na forma como a cultura digital está a alterar a relação dos museus com os públicos que servem.

3 O livro em recensão divide-se em nove secções temáticas e inclui 28 capítulos que procuram traçar contextos e práticas contemporâneas digitais com enfoque nos museus, reunindo ensaios de artistas, académicos, programadores e profissionais de museus, que se debruçam sobre a mudança de paradigmas, perspectivas e investigações, desafiando os museus e os seus profissionais a pensar e a trabalhar de forma diferente, implicando novas estratégias, práticas e procedimentos. Tal como sublinham Tula Giannini e Jonathan P. Bowen, os públicos têm, hoje em dia, mais acesso a tecnologias do que em qualquer outro momento da história, e os museus querendo ir ao encontro das necessidades dos visitantes não podem escapar a essa realidade (p. 574).

4 Dos vários capítulos transparece a multidisciplinariedade do museu como parte integrante de um ecossistema digital e como espaço de cruzamento de diversos conhecimentos e tecnologias que ao longo da sua história tem desenvolvido novas formas de aceder e dar acesso à informação e ao conhecimento.

5 Na secção introdutória os editores apresentam dois capítulos a partir dos quais traçam os antecedentes da cultura digital e do modo como esta marca actualmente todos os aspectos da vida humana - em que o espaço entre digital e físico, real e virtual se dilui, alterando comportamentos, expectativas, sensibilidades e formas de pensar (p. 21). É também a partir deste contexto que se perspectiva a redefinição da experiência museal, pois os museus e os públicos estão a adoptar novas formas de envolvimento, sendo que os museus procuram ir ao encontro das expectativas e dos comportamentos dos públicos em ambiente digital (p. 45).

6 A secção "Philosophy and Theory», que inclui contributos de Gareth Polmeer, Tula Giannini e de Jonathan P. Bowen, parte do passado para o presente e tece considerações sobre o significado de cultura digital nos museus e de como esta deve implicar o desenvolvimento de uma identidade própria das instituições culturais, através das colecções, dos públicos, do espaço físico e do virtual, das experiências e das competências (p. 64), questionando o posicionamento dos museus numa crescente rede de identidades culturais virtuais, em que o ecossistema digital é também um espaço de contestação e participação (p. 108).

7 Sob a temática «Exhibitions» são apresentados quatro capítulos, da autoria de Deborah Turnbull Tillman, Nick Lambert, Tula Giannini e Jonathan P. Bowen, que atentam em aspectos relacionados com a arte digital e as exposições, e como o incremento do digital está a influenciar a forma de ver e percepcionar a arte. Neste sentido, os museus são desafiados pelo imperativo de expansão além dos seus limites físicos, e de conexão com os públicos, através de experiências imersivas, possibilitando que também os públicos sejam curadores digitais das suas experiências (p. 191).

8 Na seç̧ão dedicada a "Collections», Douglas Dodds, Patrícia Falcão, Tom Ensom, Stuart Dunn, Graeme Earl, Anna Foka, Will Wootton destacam aspectos e potencialidades da 
digitalização das colecções, assim como das colecções de arte digital nos museus. Defende-se que os museus têm de desenvolver estratégias digitais de forma transversal que lhes permitam, entre outras formas, ir ao encontro das expectativas dos públicos, dos skateholders internos e externos, valorizando e preservando as suas colecções, assim como enfrentar o desafio das colecções digitais que dependem de tecnologia em risco de rápida obsolescência.

9 Em «Audiences» Ross Parry, Catherine Devine, Matt Tarr, Giuliano Gaia, Stefania Boiano, Ann Borda e Sara Devine apontam a importância dos públicos no contexto virtual e digital, que capacitados pelas tecnologias digitais têm novas expectativas de envolvimento. Sublinha-se o papel dos museus enquanto potenciadores de novas formas de pensar sobre o mundo e a possibilidade de poderem construir relações através dos diferentes meios digitais, criando significado entre o objecto, o conteúdo, o contentor e o público. A partir da presença real-física e real-digital, os museus poderão contribuir para a construção de novos significados no espaço físico e virtual.

Segue-se uma seç̧ão de textos sobre «Digital Artists», na qual Andy Lomas, Ernest Edmonds, Francesca Franco, Carla Gannis, Tula Giannini e Rachel Ara, apresentam o trabalho de alguns artistas com práticas contemporâneas digitais e reflectem sobre como a emersão nos meios digitais está a afectar os sentidos da cor, luz, espaço e tempo. A arte digital, nas suas múltiplas formas, ao utilizar ferramentas digitais para "fazer diferente", altera a nossa forma de ver, os nossos sentidos e o sentido estético. As tecnologias digitais ao serviço de práticas artísticas causam impacto nos museus e, em particular, nos museus de arte.

11 Na secção sobre «Education» Bruce Wands, Rosanna Flouty, Tula Giannini e Jonathan P. Bowen debruçam-se sobre as competências dos profissionais, sobre a ausência de programas formativos que respondam aos impactos provocados pela introdução das tecnologias digitais. São identificadas também limitações ou a inexistência de competências digitais e tecnológicas dos profissionais, sendo mencionados alguns grupos de trabalho e projectos formativos que têm surgido e que procuram responder à qualificação e à actualização de competências. Neste sentido, tal como defendido por Carvalho e Matos (2018) em relação à realidade portuguesa, é essencial dotar os profissionais de museus de competências para responder aos desafios da era digital, cujas potencialidades de aplicação atravessam as diferentes áreas de actuação dos museus: gestão, comunicação, educação, exposição, gestão de colecções e envolvimento de públicos. No que concerne à formação, também na realidade portuguesa se identificam lacunas quanto à oferta disponibilizada, quer no contexto da formação formal como não formal (Carvalho e Matos 2018).

12 A penúltima secção de textos «Libraries and Archives» inclui dois capítulos, de Stephen J. Bury e Judith Siefring respectivamente, frisando a importância e o potencial da colaboração entre museus, bibliotecas, centros de documentação e arquivos para construir narrativas e significados com os públicos.

13 Na última secção temática, «Digital Future», Seb Chan, Courtney Johnston, Tula Giannini, Ann Borda e Jonathan P. Bowen lançam algumas pistas sobre o futuro dos museus com respeito aos desenvolvimentos da cultura digital. A identificação com o espaço físico do museu continua a ser em muitos casos uma prerrogativa, um espaço localizado num determinado tempo e lugar, mas que se expandiu para o ciberespaço e deu origem a uma identidade digital. Os museus do século XXI actuam no ecossistema da cultura 
digital e, consequentemente, buscam uma nova identidade à medida que lidam com as percepções do público sobre o passado e a promessa do futuro.

14 Apesar das reflexões e debates que têm surgido nos últimos anos (Carvalho e Matos 2018, entre outros) sobre o uso das tecnologias nos museus e sobre o papel que devem ou não desempenhar, entre a instituição e os públicos, as práticas e as atitudes, estas interrogações continuam ainda a ser pertinentes e potenciadoras de novas abordagens e desenvolvimentos. Os museus não existem num vacum (Carvalho e Matos 2018), logo terão de se transformar e adaptar à era digital. A cultura digital está a alterar a percepção do ser humano, a nossa forma de estar, de fazer, de pensar, e quase todos os aspectos da vida estão entrelaçados com a esfera do digital. Neste sentido, compreender a cultura digital é essencial para a relevância dos museus do século XXI. Mas situados os museus no mundo pós-digital, no ecossistema digital, num ponto de vantagem sobre o potencial da interacção interior/exterior, participação/colaboração, físico/digital, os museus terão de desenvolver novas formas de pensar e trabalhar, novas estratégias e práticas que procurem ir ao encontro das expectativas e dos comportamentos dos públicos em ambiente físico e digital, transmitindo e criando significados através das suas colecções.

\section{BIBLIOGRAFIA}

Bowen, Jonathan P., e Tula Giannini. 2014. “Digitalism: The New Realism?” In EVA London 2014: Proceedings of the EVA London 2014 on Electronic Visualisation and the Arts, 324-331.

Carvalho, Ana., e Alexandre Matos. 2018. "Museum Professionals in a Digital World: Insights from a Case Study in Portugal." Museum International (Special Issue: Museums in a Digital World) 70 (277278): 34-47.

Giannini, Tula, e Jonathan P. Bowen. 2016. Curating Digital Life and Culture: Art and Information. In Proceedings of the EVA London 2014 on Electronic Visualisation and the Arts, 237-244.

\section{NOTAS}

1. A autora escreve de acordo com a antiga ortografia.

\section{AUTORES}

\section{MARGARIDA MELO SAMPAIO}

Investigadora independente, Portugal, margaridasampayo@gmail.com 